Article

\title{
Estimating Single-Tree Crown Biomass of Norway Spruce by Airborne Laser Scanning: A Comparison of Methods with and without the Use of Terrestrial Laser Scanning to Obtain the Ground Reference Data
}

\author{
Marius Hauglin ${ }^{1, *}$, Terje Gobakken ${ }^{1}$, Rasmus Astrup ${ }^{2}$, Liviu Ene ${ }^{1}$ and Erik Nasset ${ }^{1}$ \\ 1 Department of Ecology and Natural Resource Management, Norwegian University of Life \\ Sciences, P.O. Box 5003, 1432 Ås, Norway; E-Mails: terje.gobakken@nmbu.no (T.G.); \\ liviu.ene@nmbu.no (L.E.); erik.naesset@nmbu.no (E.N.) \\ 2 The Norwegian Forest and Landscape Institute, P.O. Box 115, 1431 Ås, Norway; \\ E-Mail: rasmus.astrup@skogoglandskap.no \\ * Author to whom correspondence should be addressed; E-Mail: marius.hauglin@nmbu.no; \\ Tel.: +47-6496-5389; Fax: +47-6496-5801.
}

Received: 14 November 2013; in revised form: 7 January 2014 / Accepted: 19 February 2014 / Published: 28 February 2014

\begin{abstract}
Several methods to conduct single-tree inventories using airborne laser scanning (ALS) have been proposed, and even terrestrial laser scanning (TLS) has recently emerged as a possible tool for the collection of forest inventory data. In the present study, a novel methodological framework for a combined use of ALS and TLS in an inventory was tested and compared to a method without the use of TLS. Single-tree Norway spruce crown biomass was predicted using an ALS-model with training data obtained by TLS. ALS and TLS data were collected for sets of sample trees, including 68 trees with both ALS and TLS data. In total, 29 destructively sampled trees were used to fit a TLS crown biomass model, which then was used to predict crown biomass in a separate set of 68 trees. This dataset was subsequently used to fit an ALS crown biomass model. When validating the model, using a separate dataset with accurately measured crown biomass obtained through destructive sampling, the mean error was $32 \%$ of the observed mean biomass. Corresponding crown biomass predictions derived with ALS-predicted diameters and the use of conventional and existing allometric models resulted in a mean error of $35 \%$. Thus, in the present study, a slight improvement, in terms of prediction accuracy, was found when using training data with ground reference values obtained by TLS.
\end{abstract}


Keywords: airborne laser scanning; terrestrial laser scanning; forest inventory; crown biomass

\section{Introduction}

Forest inventories are essential for the sustainable management of forest resources. An increasing number of forest inventories are based on data collected with airborne laser scanning (ALS) [1]. While commercial and operational ALS-based forest inventories most frequently are conducted according to the so-called area-based approach, as described by Næsset [2], methods targeting single trees have also been proposed [3-6]. The latter methods usually require ALS data with higher resolution, but intend to give information on a single-tree level, contrary to the area-based information provided by the former. Although not as widely used as the area-based method at present, the use of single-tree forest inventories might increase in the future. This will depend on the ongoing technological and methodological research and development, the need for single-tree data and future costs for data acquisition. The potential of estimating single-tree characteristics by ALS has been investigated in several studies, including stem volume [4,7], stem diameter [8], crown base height [9], leaf area index [10] and biomass $[8,11,12]$.

The same laser ranging principles as in the airborne scanning systems have also been applied in scanning from fixed positions on the ground, commonly known as terrestrial laser scanning (TLS). The use of TLS in forestry has not become operational to the same degree as the use of ALS, but several applications, such as the estimation of tree position and diameter at breast height (DBH), have been investigated [13-17]. There are also studies presenting procedures to estimate, e.g., total above-ground biomass from TLS data [17,18]. Hauglin et al. [19] and Kankare et al. [20] have described methods to estimate crown biomass using TLS.

ALS-based forest inventories are typically carried out with ground reference data obtained from manual field measurements of, e.g., DBH and tree height, on selected sample trees collected in sample plot surveys. This reference data is then used together with the ALS data to build predictive models. Depending on the ongoing technological and methodological research and development, TLS might become a tool for the collection of ground reference data in ALS-based inventories, possibly replacing manual registrations. The use of TLS can even enable objective and detailed registrations of features that are practically unobtainable through conventional field measurements, such as the spatial distribution of biological matter or properties related to the detailed structure of the trees.

In the last ten years, there has been an increased interest in the use of logging residues for bioenergy purposes, i.e., biomass otherwise left in the forest during the logging [21]. When logging residues become a commercial product from the forest, the potential amount should be quantified as part of the forest inventory, to improve planning and management.

Estimation of forest biomass using ALS usually requires the use of model training data obtained through field measurements and the use of allometric models, typically linking the field measured DBH and tree height with a given biophysical property [8,21-23]. For Norway spruce (Picea abies (L.) Karst.) - the tree species considered in the present study-the crown biomass can vary 
considerably in relation to $\mathrm{DBH}$ and tree height, and predictions of Norway spruce crown biomass from allometric models has larger errors than corresponding predictions of, e.g., stem volume [24,25]. Hauglin et al. [19] showed that Norway spruce crown biomass estimates can be derived from TLS data with a higher accuracy than by conventional field measurements and existing allometric models, making the estimation of crown biomass a suitable test case for replacing manual field registrations with TLS.

We propose in the present study a procedure for ALS-based estimation of single-tree crown biomass using training data with ground reference values obtained through TLS. An independently developed TLS-based model was used to obtain the ground reference data, and automated single-tree segmentation was used in the assignment of ALS data to individual trees.

To test our proposed procedure with TLS as the ground reference data in an ALS-based inventory, we estimated single-tree crown biomass of Norway spruce and evaluated the proposed procedure with an independent dataset consisting of trees with accurately measured crown biomass obtained with destructive sampling. The prediction accuracies were compared to the accuracies of crown biomass predictions obtained with ALS-predicted DBH and the use of an existing allometric model, i.e., predictions obtained without the use of TLS data.

The aim of the present study was to assess the use of TLS in the process of fitting predictive models in an ALS single-tree forest inventory, by predicting crown biomass following each of the two approaches outlined above, and compare the predictions in an independent validation dataset.

\section{Materials and Methods}

\subsection{Study Area}

The study area is located in Aurskog-Høland municipality (59 50' N 11 ${ }^{\circ} 30^{\prime} \mathrm{E}, 120-390 \mathrm{~m}$ above sea level) in the south-eastern part of Norway (Figure 1, left). The total area of Aurskog-Høland is 960 $\mathrm{km}^{2}$ with $670 \mathrm{~km}^{2}$ of productive forest. The forest type is boreal with Norway spruce and Scots pine (Pinus sylvestris L.) as the dominant tree species. The topography varies from relatively flat to gentle slopes and hills.

Figure 1. Location of the study area (left) and the locations of the field and remote sensing data within the study area (right). TLS, terrestrial laser scanning; ALS, airborne laser scanning.

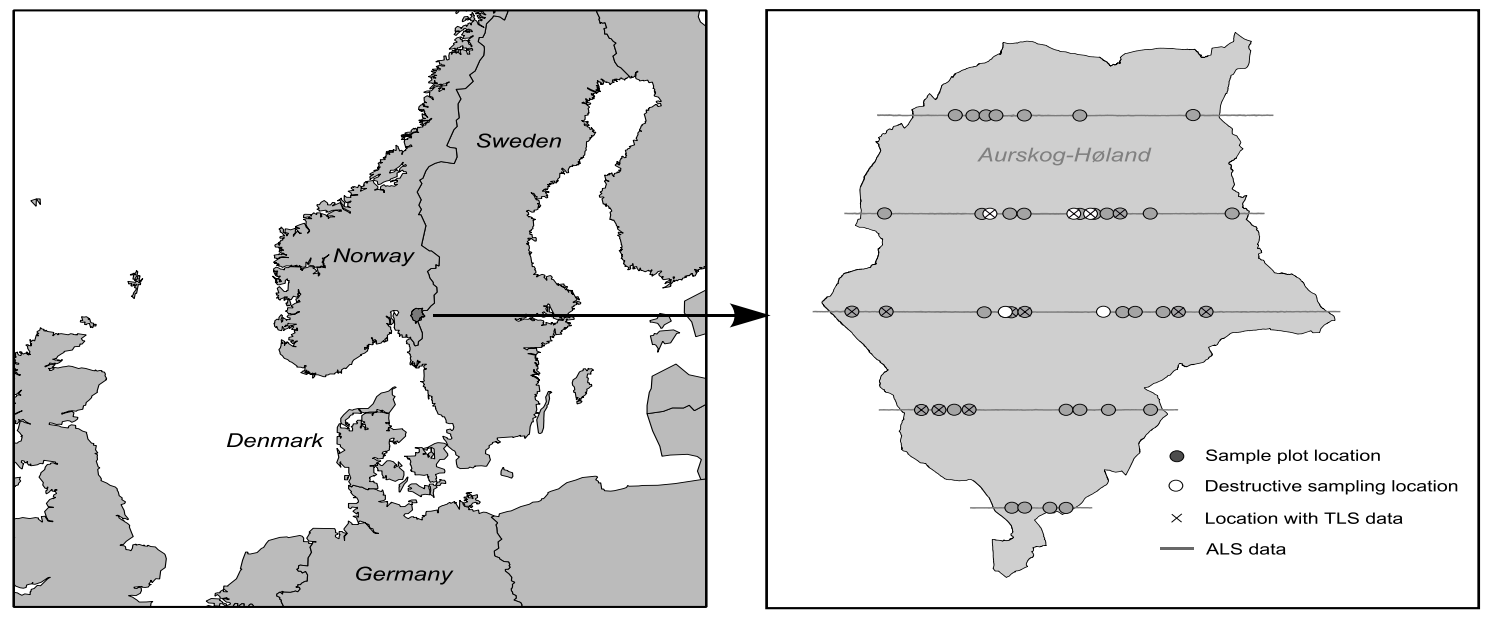




\subsection{Forest Inventory: Stratification}

An operational forest inventory was carried out in the study area, including a stratification of the productive forest. This stratification was utilized in collection of the field data used in the present study. The stratification was based on digital aerial photographs acquired in June, 2005, with a Vexcel UltraCam D camera. Through digital stereo photogrammetry, forest characteristics were interpreted manually by photo-interpretation of every stand, including stand borders, dominant tree species, site productivity and age class (see further details in Næsset et al. [26]). The existing inventory was used as auxiliary information in the interpretation process.

\subsection{Field Data}

Single-tree data from two field campaigns in the study area were used in the present study: one dataset with single-tree measurements on 40 sample plots and another with single-tree measurements obtained with destructive sampling on five sample locations. The 40 sample plot locations are marked by filled circles in Figure 1 and described in Subsection 2.3.1. The five destructive sampling locations are marked with hollow circles in Figure 1 and described further in Section 2.3.2. The data from the five locations with destructive sampling were in the present study split in two, resulting in the three datasets used in the analysis (Table 1).

Table 1. Characteristics of the three datasets used in the present study; diameter at breast height (DBH) and field measured dry weight crown biomass (BR).

\begin{tabular}{ccccccccc}
\hline & \multicolumn{3}{c}{ DBH $(\mathbf{c m})$} & \multicolumn{3}{c}{ BR $(\mathbf{k g})$} & $\boldsymbol{n}$ \\
\hline & min & $\max$ & mean & $\min$ & $\max$ & mean \\
\hline TLS model training dataset & 9.7 & 39.8 & 22.2 & 8.9 & 152.3 & 60.7 & 29 \\
ALS model training dataset & 7.1 & 37.7 & 19.6 & - & - & - & 68 \\
Validation dataset & 16.6 & 40.3 & 25.4 & 28.6 & 163.2 & 75.7 & 17 \\
\hline
\end{tabular}

\subsubsection{Sample Plot Data}

The sample plot field registrations were carried out in the fall, 2007, and winter, 2007-2008, on 40 circular plots of size $1000 \mathrm{~m}^{2}$ and $500 \mathrm{~m}^{2}$, laid out in the mature productive forest of the study area (Figure 1, right). Single-tree data used in the present study were from a subset of 11 plots. The sample plots were initially used in other studies, and some constraints were posed regarding the location of the plots (see Maltamo et al. [27] for details). Within each of these plots, all trees with $\mathrm{DBH} \geq 5 \mathrm{~cm}$ were callipered, and tree coordinates relative to the plot center were registered using a total station. The plot center coordinates were determined by differential Global Navigation Satellite System (dGNSS), using dual-frequency receivers observing the pseudo-range and carrier phase of the Global Positioning System (GPS) and the Global Navigation Satellite System (GLONASS). Based on the accuracy reported by the post-processing software and accuracies reported for comparable conditions in

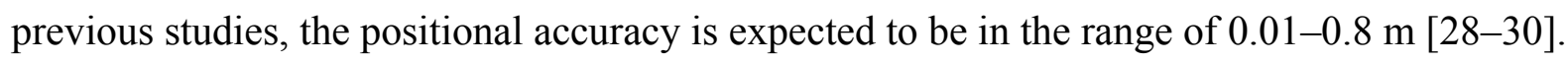

The observed number of trees on the 40 sample plots were used to guide the segmentation algorithm in which the ALS data were allocated to single-tree segments (Section 2.5.1), and a subset of 
the individual Norway spruce trees within 11 of the 40 plots (68 trees) were used in the present study (see Section 2.4.1). The selection of the 68 trees was determined by the result of the segmentation procedure (to be described in detail in Section 2.5.1) and field measured tree positions: only trees with one single field measured tree position within a segment were used.

\subsubsection{Destructive Sampling Data}

Field data with accurately measured crown biomass were collected in June, 2009. A total of 49 spruce trees were selected from five locations in the study. The five locations were chosen from potential sites in the intersections of the east-west-oriented strips of ALS data and forest roads, covering a range from poor to good site productivity in mature forest (Figure 1, right). Within each location, sample trees of Norway spruce were selected in a consecutive fashion. Further details about the selection procedure are given in Hauglin et al. [11]. The 49 trees were felled, and the raw weight of all the branches (including needles and dead branches) of each tree was obtained by weighing the tree before and after the branches were cut off. The weighing was done with a mobile lift mounted on a truck. A Teraoka Seiko OCS-XZL digital scale with a load capacity of $3000 \mathrm{~kg}$ and an accuracy of $1 \mathrm{~kg}$ was used. Samples of entire branches were selected among the living branches of each tree and dried, in order to determine the dry weight. The drying was done at $103 \pm 1{ }^{\circ} \mathrm{C}$ until constant mass and a wet to dry weight ratio was calculated for each sampled branch. For each tree, a wet to dry weight ratio was then calculated as the weighted mean of the ratios obtained from the samples, with the diameters of the branches used as weights. Finally, the total dry weight biomass of the branches for each tree (denoted as BR) was calculated as the wet weight of the branches multiplied with the calculated tree-specific wet-to-dry weight ratio. Further details about the determination of the dry weight are given in Hauglin et al. [11].

The coordinates of each tree in this dataset were obtained in a two-step procedure: (1) the location of each tree relative to two local reference points was accurately measured with a total station; and (2) the coordinates of the two reference points were obtained by dGNSS, using the same procedure as described for the sample plot dataset (Subsection 2.3.1).

In the present study, this dataset with accurately measured crown biomass was split into two: the first three locations (containing 29 trees) were selected and used as training data for a TLS crown biomass model (TLS model training dataset). The remaining two locations (with 20 trees) were used for validation (validation dataset). Not all trees present at the locations were destructively sampled, and three of the initial 20 sampled trees were discarded from the validation dataset, since their assigned crown segments also contained other trees (see Section 2.5.1).

Characteristics of the trees in the data material used in the present study are summarized in Table 1.

\subsection{Laser Scanner Data}

\subsubsection{ALS Data}

ALS data were collected along five strips oriented in the east-west direction and located $9 \mathrm{~km}$ apart (Figure 1, right). The ALS dataset was collected in June, 2006, with an Optech ALTM 3100 sensor on a fixed-wing aircraft. The average flying altitude was 800 meters above ground. The pulse repetition 
frequency was $100 \mathrm{kHz}$, the scan frequency $70 \mathrm{~Hz}$ and the scan angle \pm 5 degrees from nadir. This gave an average point density on the ground of $7-8 \mathrm{~m}^{-2}$. Up to four echoes were recorded for each pulse. The geo-referenced planimetric coordinates and the ellipsoidal height values were determined by the vendor for all echoes. The ALS data are further described in Breidenbach et al. [31].

The classification of echoes into ground and vegetation echoes was carried out by iteratively fitting a triangular irregular network (TIN) from below, as described by Axelsson [32]. Points were in an iterative fashion added to the ground if they were within given threshold values. Echoes classified as ground were used to construct a TIN surface. The height above ground was calculated for all echoes by subtracting the respective TIN heights from the ellipsoidal heights.

\subsubsection{TLS Data}

TLS data were obtained for 11 of the 40 sample plots (Section 2.3.1) and at three of the five locations with destructively sampled trees (Section 2.3.2 and Table 1). The TLS data were acquired during the summer of 2009. TLS data from multiple scans of 97 trees were used in the present study, and all scans were acquired with a levelled Leica HDS6000 phase-shift scanner. The scanning was done with a horizontal and vertical angle increment of the laser measurements of 0.036 degrees. This corresponds to a point spacing of $15.9 \mathrm{~mm}$ at a $25-\mathrm{m}$ distance from the scanner. The scanner had a beam diameter when leaving the instrument of $3 \mathrm{~mm}$ and a beam divergence of $0.11 \mathrm{mrad}$, resulting in an $8-\mathrm{mm}$ footprint at $25 \mathrm{~m}$. The scanner had a maximum measurement range of $79 \mathrm{~m}$. A full $360 \times 310$ degrees scan (the scanners maximum field-of-view) was performed from each scanner position, i.e., both hemispheres, excluding the ground directly beneath the scanner. The Leica Cyclone software (version 6.0) was used to register the individual scans, with $3.5 \mathrm{~mm}$ as the average mean absolute error reported by the software.

The scan positions were chosen so that each sample tree was scanned from at least two positions, with the distance to the sample trees being in the range of 1-15 m. Furthermore, the scanner position was chosen so that the top of each of the sample trees preferably was visible in at least one scan (Figure 2, left). For the scanning of the sample plots, five scans were performed at each plot: one scan from the plot center and one scan from positions towards each of the cardinal directions from the center position (Figure 2, right). Scan targets were used in order to register (merge) the scans correctly. The scanner positions were locally referenced by measuring distance and bearing to two known auxiliary points using a total station. The auxiliary points were geo-referenced by the differential Global Navigation Satellite System and were purposely placed in areas with large gaps in the canopy or in nearby open-sky areas, such as clear-cuttings. Satellite data were logged for $>30 \mathrm{~min}$, and the distance to the base station was within the range of $20-45 \mathrm{~km}$ for all the auxiliary points. Based on the results found by Andersen et al. [29], we expect the true error of these positions to be well below $0.5 \mathrm{~m}$; in most cases, much lower. The co-registration of the TLS and ALS data were thus implicitly performed through the accurate geo-referencing of the two remote sensing datasets. 
Figure 2. Example of scanner locations at the sample plots (left) and on locations with destructive sampled trees (right).



\subsection{Calculations and Analysis}

Single-tree crown biomass was predicted from ALS data using two approaches (outlined in Figure 3) and the results compared. In the first approach, a TLS-crown biomass model, trained with a separate dataset, was used to predict ground reference values for a set of scanned trees, which were subsequently used as training data in predictive ALS-crown biomass models (Figure 3, right). This approach was compared to ALS-based predictions without the use of TLS data, that is, the ALS model training data were obtained by conventional field measurements of $\mathrm{DBH}$. The predictions of crown biomass followed in this case the procedure proposed by Popescu [8], in which DBH is the property that is modelled with the ALS-based predictive models. To get crown biomass estimates, one then has to use the predicted DBH with an existing allometric model. An alternative here could have been to use the existing allometric biomass model already at the stage of preparing the training data for the ALS models and let the crown biomass be the property predicted directly by the ALS-based model. This was not done in the present study, because results from the study by Popescu indicated that the former approach yields a higher accuracy [8]. 
Figure 3. Outline of the two approaches that were compared in the present study: the approach with the use of TLS data (A) and the approach without the use of TLS data (B). In the former approach, crown biomass modelled from TLS data was used as the ground reference values in the subsequent ALS modelling process. The two methods were validated using one set of destructively sampled trees.

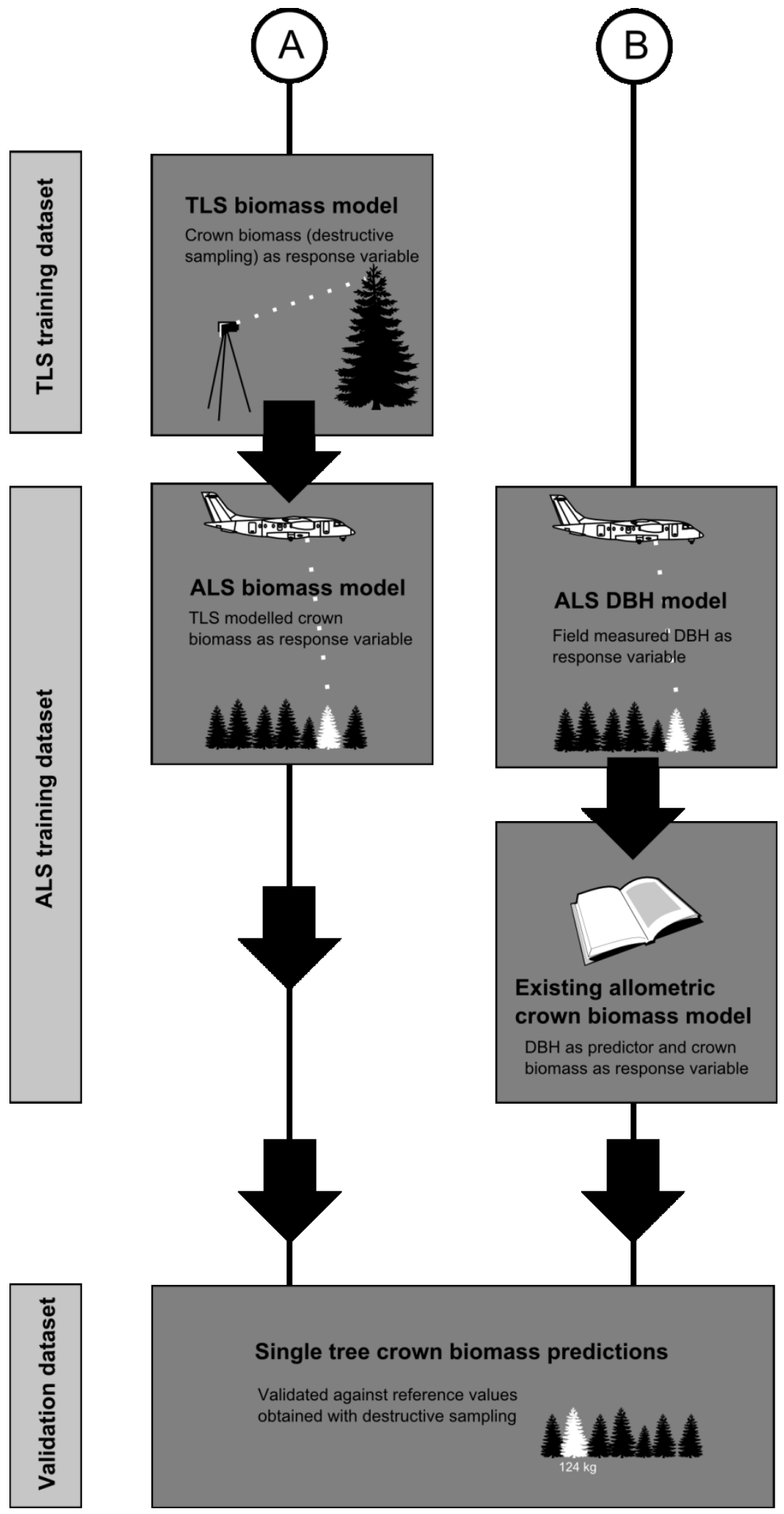




\subsubsection{Single-Tree Segmentation}

The ALS data were in the present study delineated into single-tree segments using a fully automated segmentation algorithm [6]. A marker-based watershed algorithm was used to delineate single-tree segments from a canopy height model. An adaptive approach was used, utilizing a priori area-based stem number predictions to guide the delineation. Data from the sample plots (Section 2.3.1) were used as training data in the prediction of stem numbers. The segmentation was carried out in a rasterized representation of the ALS data, but the crown segments used in the subsequent analysis were constructed as a convex hull in the horizontal plane of the ALS echoes within each raster segment (depicted in Figure 4). The reader is referred to Ene et al. [6] for further details about the segmentation algorithm.

Figure 4. Single-tree segments for some of the sample trees; field measured tree positions of destructively sampled trees (dots) and other trees (stars). Tree \#4 was linked to the segment with the nearest centroid (see Section 2.5.1). The segment containing Tree \#7 was excluded from the validation dataset, since it also encompassed a tree without field measured crown biomass.

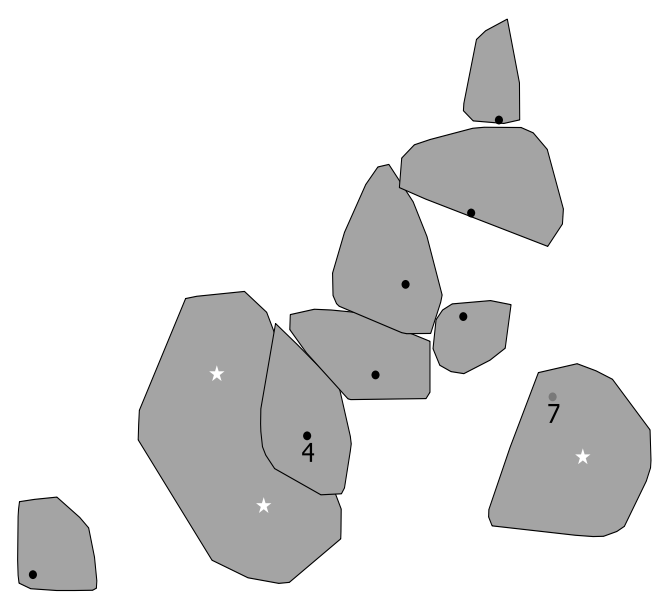

Automatic delineation of tree crowns will usually result in some erroneous segments [33]. These can be caused by commission errors (segments of non-existing trees) or omission errors. Commission errors are typically caused by delineating large tree crowns into multiple segments, whereas trees omitted in the segmentation procedure are typically small or suppressed. Combining multiple adjacent crowns into one single segment will also lead to one or more trees being omitted. In the present study, the ALS-derived segments were handled according to the following rules:

- Field measured trees were linked to ALS-derived crown segments if the field measured stem positions were inside the segment.

- Since the procedure allows for overlapping segments, a field tree with a position inside more than one segment would be connected to the segment with the shortest distance from its centroid to the field tree position.

- ALS model training data: only trees with one single field measured tree position within a segment were used. 
- Validation data: If more than one field measured tree was inside a segment the sum of the crown biomass for all the field trees positioned inside, the segment was used as the reference crown biomass.

- Validation data: Segments encompassing trees that were not destructively sampled were excluded from the validation dataset, since the reference biomass was not known for the whole segment.

Some of the rules are illustrated in Figure 4. In the present validation data material, no segments contained more than one destructively sampled tree, whereas three destructively sampled trees were within segments encompassing other trees, and these segments were therefore excluded from the validation dataset.

\subsubsection{ALS-Derived Variables}

For each single-tree segment, the crown base height was estimated from the height of the ALS echoes, and echoes above the crown base height were denoted as crown echoes. The method described by Solberg et al. [5] was used; the crown base height was set at the height decile with the largest distance downwards to the next decile. The minimum crown base height was set at $0.85 \mathrm{~m}$ above ground.

In order to use the ALS data for the prediction of crown biomass, variables were computed from the laser echoes allocated to each individual tree-crown (i.e., the crown echoes). Hauglin et al. [11] found that a crown volume was a good predictor for crown biomass, and in the present study, a crown volume derived from the crown echoes by means of a radial basis function was used (denoted CRvol). In order to preserve the internal spatial relationship between the crown echoes, the ellipsoidal heights were used when calculating the crown volume. This crown volume was computed using a procedure to construct a closed surface from scattered data points: The crown echoes were first divided into horizontal layers, and the outermost echoes were identified in each layer. An interpolated surface was constructed from these "surface" points, and the crown volume was then computed as the volume inside this surface. The surface constructed with radial-basis functions is related to a three-dimensional convex hull, but is more flexible and allows for non-convex shapes. The reader is referred to Hauglin et al. [11] for a detailed description of the computation of this crown volume and Carr et al. [34] for a more general description of surface reconstruction with radial basis functions.

Popescu [8] successfully estimated DBH from ALS data, with tree height and crown diameter as predictor variables in a linear regression model. In the present study, a similar model was used, with the maximum above-ground height for the echoes within a tree segment (Hmax) representing the tree height and the crown diameter calculated as the mean of the two sides of an axis-aligned minimum bounding box of the crown echoes within each tree segment (denoted CRdiam). Note that in Popescu [8], the crown diameter was calculated in a slightly different way.

\subsubsection{TLS-Derived Variables}

Features were extracted from the TLS data and used to create variables included in a subsequent regression analysis. Hauglin et al. [19] found a strong relationship between TLS-derived crown measurements and crown biomass. In the present study, a similar set of TLS features were derived 
from manual measurements of individual tree crowns in the unified TLS data. The manual measurements were carried out using a 3D point cloud viewer with an additional two-dimensional plot of a horizontal and a vertical slice of the data (Figure 5). The horizontal and vertical slices were of $1 \mathrm{~m}$ and $0.6 \mathrm{~m}$ thickness, respectively. The $r g l$ package(version 0.93) in the programming language, $\mathrm{R}$ [35], was used to build the point cloud viewer. The crown projection onto the horizontal plane was measured as a polygon area and the crown width as the horizontal distance from one side of the crown to the other. Both measurements were performed at heights corresponding to 10, 20, 40,60 and 80 percent of the crown length. The crown length was calculated as the vertical distance from the crown base height and the highest recorded TLS laser echo attributed to the given tree. The crown base height was manually determined by visually inspecting the TLS data, and we defined it to correspond to the lowermost part of the lowermost living branch of the tree. An image from the manual measurements in the TLS data is given in Figure 5. The variables computed from the crown measurements are described and listed in Table 2.

Figure 5. From the manual measurements in the TLS data: overview (left), crown area (middle) and crown width (right). The gradient colors are derived from the height of the laser echoes, and are added for visualization purposes.



Table 2. Description of the variables derived from crown measurements in the TLS data.

\begin{tabular}{|c|c|}
\hline Variable & Description \\
\hline$C R_{\text {length }}$ & $\begin{array}{l}\text { Crown length. Vertical distance from the crown base height to the highest laser } \\
\text { echo assigned to the tree. }\end{array}$ \\
\hline$C R A_{10, \ldots, 80}$ & $\begin{array}{l}\text { Crown projection area. Area of the crown projection measured at heights } \\
\text { corresponding to } 10,20,40,60 \text { and } 80 \text { percent of the crown length. }\end{array}$ \\
\hline$C R A_{\text {sum }}$ & $\begin{array}{l}\text { Crown projection area sum. The sum of the area of the crown projection } \\
\text { measurements at heights corresponding to } 10,20,40,60 \text { and } 80 \text { percent of the } \\
\text { crown length. }\end{array}$ \\
\hline$C R W_{10, . ., 80}$ & $\begin{array}{l}\text { Crown width. The crown width measured at heights corresponding to } 10,20,40,60 \\
\text { and } 80 \text { percent of the crown length. }\end{array}$ \\
\hline$C R W_{\text {sum }}$ & $\begin{array}{l}\text { Crown width sum. The sum of the crown width measurements at heights } \\
\text { corresponding to } 10,20,40,60 \text { and } 80 \text { percent of the crown length. }\end{array}$ \\
\hline
\end{tabular}




\subsubsection{Crown Biomass Predicted Using TLS to Obtain the Reference Values}

In order to get the ground reference crown biomass for the ALS training data, a TLS-based model was used. Following the approach described in Hauglin et al. [19], dry weight crown biomass was predicted using a random forest regression model with the TLS-derived predictor variables described in Table 2. The TLS training data, comprising 29 destructively sampled trees (Section 2.3 .2 and Table 1), were used to fit this TLS biomass model. A random forest model was chosen, because it was found to be a suitable model for a similar modelling task by Hauglin et al. [19]. The implementation of the random forest algorithm in the randomForest package of the statistical software, $\mathrm{R}$, was used, and further details about this model in the present study can be found in Hauglin et al. [19]. For a general discussion of the principles and use of the random forest algorithm, the reader is referred to Breiman [36] or Hastie et al. [37]. The relative importance of the TLS-derived variables was obtained by inspecting the out-of-bag performance of the random forest model for each variable. Unscaled permutation importance was used.

A linear regression model with the ALS-derived crown volume as the predictor variable and the TLS-modelled crown biomass as the response variable was fitted to the ALS training data and used to predict crown biomass in the validation dataset:

$$
\widehat{B R}=\beta_{0}+\beta_{1} C R v o l+\varepsilon
$$

where $\beta_{0}$ and $\beta_{1}$ are parameters to be estimated and $\varepsilon$ is an error term, assumed to be normally distributed with mean zero and constant variance.

This approach is labeled " $A$ " in Figure 3.

\subsubsection{Crown Biomass Predicted Using an Existing Allometric Model}

The method proposed in the previous section was compared to an approach using ALS-predicted DBH and an existing allometric biomass model. In this approach, we first modelled DBH with ALS-derived features, and then, this ALS-predicted DBH was used with an existing allometric model to derive crown biomass (Figure 3, right). ALS-derived height and crown diameter were first used to model DBH with a linear model:

$$
\widehat{D B H}=\beta_{0}+\beta_{1} \text { CRdiam }+\beta_{2} \operatorname{Hmax}+\varepsilon
$$

where $\beta_{0}, \beta_{1}$ and $\beta_{2}$ are parameters to be estimated and $\varepsilon$ is a normally distributed error term. A species-specific allometric crown biomass model by Marklund [25] was then used to derive crown biomass for the trees in the validation dataset using the ALS-derived $D B H$ :

$$
\widehat{B R}=e^{-1.2804+8.5242 \cdot \frac{D B H}{D B H+13}}
$$

The method described in this section corresponds, with some divergence related to the calculation of the crown diameter, to the method described by Popescu [8], as explained in Section 2.5.2. This approach is labeled "B" in Figure 3. 


\subsubsection{Final Validation}

The two ALS-based approaches (Section 2.5.4 and 2.5.5) were used to predict crown biomass for the 17 trees in the separate validation dataset. The predictions were then compared to accurate field measurements obtained by destructive sampling and statistics computed to assess the prediction accuracy.

The coefficient of determination $\left(R^{2}\right)$ of the models was inspected for an indication of the model fit. The $R^{2}$ values were computed for all the models as:

$$
R^{2}=\rho(\text { fitted values, observed values })^{2}
$$

where $\rho$ is the Pearson's correlation.

The accuracy of the predictions was assessed by computing the root mean square error (RMSE) of the predicted values. In the present study, RMSE and bias was calculated in percent of the mean observed value, i.e.,

$$
R M S E \%=\frac{R M S E}{\frac{\sum_{i=1}^{n} B R_{i}}{n}} 100
$$

where $n$ is the number of trees and $\widehat{B R}$ is the predicted crown biomass, and:

$$
\text { bias } \%=\frac{\text { bias }}{\frac{\sum_{i=1}^{n} B R_{i}}{n}} 100
$$

The significance of the difference between the observed and the predicted values and the difference between the errors from the two approaches were assessed with paired $t$-tests.

\section{Results}

Estimation of single-tree crown biomass from ALS data was carried out following two approaches, one with the use of TLS-data in the modelling process and one without the use of TLS-data. The results from the two different approaches were compared using accurately measured reference values obtained with destructive sampling. In the first approach, a random forest regression model linking crown biomass to TLS derived variables (Tables 2 and 3) was fit to the TLS training dataset, consisting of 29 trees. The $R^{2}$ for this model was 0.80 , and the out-of-bag prediction errors corresponded to an RMSE of $34.0 \%$. The relative importance of the variables in this TLS model is given in Table 3, and it shows that the cumulative crown area and width are the two variables with the largest contribution.

The TLS model was then used to predict ground reference crown biomass in the ALS model training dataset (Figure 3, right).

The ALS model training dataset was the next step used to fit a linear model with an ALS-derived crown volume as the explanatory variable and crown biomass as the response variable. The $R^{2}$ value for this model was 0.50 (Table 4). A leave-one-out cross-validation of this model gave an RMSE of $43.1 \%$, and predictions for the validation dataset with this approach, i.e., using the TLS data, resulted in an RMSE of $32.4 \%$ (Table 4 and Figure 6). 
Table 3. Ranking of the TLS-derived variables. The importance score based on the "out-of-bag" predictions in the random forest model; here, given relative to the lowest ranked variable, which was given the value of one.

\begin{tabular}{lc}
\hline Variable & Relative score \\
\hline$C R A_{\text {sum }}$ & 89 \\
$C R W_{\text {sum }}$ & 69 \\
$C R A_{10}$ & 53 \\
$C R A_{40}$ & 52 \\
$C R A_{20}$ & 45 \\
$C R W_{40}$ & 16 \\
$C R_{\text {length }}$ & 12 \\
$C R W_{60}$ & 10 \\
$C R W_{10}$ & 7 \\
$C R A_{60}$ & 6 \\
$C R W_{20}$ & 5 \\
$C R W_{80}$ & 2 \\
$C R A_{80}$ & 1 \\
\hline
\end{tabular}

Table 4. Model and validation statistics for the ALS crown biomass model with the use of TLS when obtaining the training data (A) and crown biomass predictions obtained with ALS-predicted DBH and the use of an existing allometric model (B). $R^{2}$ from the model-fitting ( $n=68)$; root mean square error $(\mathrm{RMSE}) \%$ and bias $\%$ from the validation $(n=17)$.

\begin{tabular}{|c|c|c|c|c|}
\hline & \multicolumn{2}{|r|}{ Model fit } & \multicolumn{2}{|c|}{ Validation } \\
\hline & Predictor variables & $R^{2}$ & RMSE\% & bias $\%$ \\
\hline A & CRvol & 0.50 & 32.4 & $10.2 \mathrm{~ns}$ \\
\hline $\mathrm{B}$ & $H \max +$ CRdiam $^{\mathrm{a}}$ & $-^{b}$ & 35.1 & $-4.3 \mathrm{~ns}$ \\
\hline
\end{tabular}

Significance levels: ns, not significant $(p>0.05) ;{ }^{a} \mathrm{DBH}$ is modelled from the ALS data, and then, an existing allometric model is used to get the crown biomass [25]; ${ }^{\mathrm{b}} R^{2}$ from the fitting of the ALS-DBH model was $0.84(n=68)$.

In the second approach, the same ALS model training dataset was used, this time to model DBH using the ALS-derived tree height and crown diameter as explanatory variables. The $R^{2}$ for this model was 0.84 , and a leave-one-out cross-validation gave an RMSE of $15.5 \%$. Using this ALS-DBH model, DBH was predicted for the 17 trees in the validation dataset and crown biomass calculated by applying an existing allometric model to the estimated DBH for each individual tree (see Section 2.5.5 for details of this approach). The validation of the latter approach resulted in an RMSE of $35.1 \%$. Validation of both approaches was carried out using the same validation dataset consisting of 17 trees, with accurately measured reference values obtained with destructive sampling (Figure 6).

No significant bias was observed for either of the two approaches in the present study (Table 4 and Figure 6). 
The difference between the errors from the two approaches was assessed with a one-sided paired $t$-test, resulting in a $p$-value of 0.08 . Thus, the method with the use of TLS was not found to be significantly better in the present study (at $\alpha=0.05$ ).

Actual parameter-values for the fitted linear regression models are given in Table 5.

Figure 6. Predicted $(\widehat{B R})$ versus ground reference crown biomass $(\mathrm{BR})$ in the validation of the two approaches for the prediction of crown biomass.

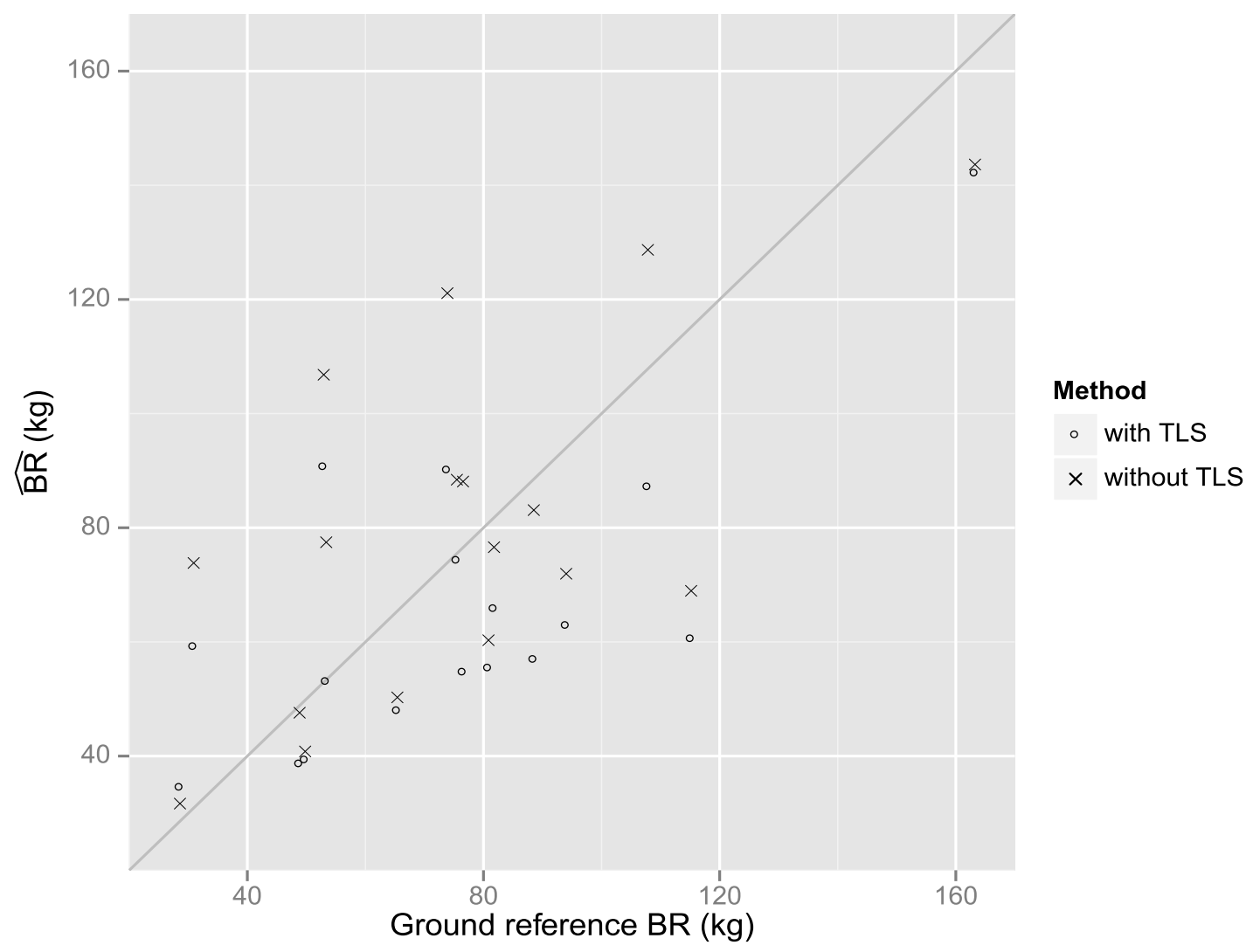

Table 5. Parameter values for the fitted linear regression models (described in Section 2.5.4).

\begin{tabular}{lccc}
\hline \multicolumn{1}{c}{ Model } & $\boldsymbol{\beta}_{\mathbf{0}}$ & $\boldsymbol{\beta}_{\mathbf{1}}$ & $\boldsymbol{\beta}_{\mathbf{2}}$ \\
\hline$\widehat{B R}=\beta_{0}+\beta_{1}$ CRvol $+\varepsilon$ & 9.59208 & 0.73589 & - \\
$\widehat{D B H}=\beta_{0}+\beta_{1}$ CRdiam $+\beta_{2}$ Hmax $+\varepsilon$ & -3.90421 & 2.83414 & 0.93242 \\
\hline
\end{tabular}

\section{Discussion}

In the present study, two approaches for the prediction of single-tree crown biomass from ALS data were compared: one with training data based on ground reference values obtained with TLS and one method without the use of TLS. The prediction accuracy was assessed using a dataset with crown biomass accurately obtained through the use of destructive sampling. The results show that good single-tree crown biomass estimates of Norway spruce can be obtained from ALS models using training data with ground reference values derived with TLS. The observed differences in terms of prediction accuracy between the two approaches were, however, small, which means that the use of TLS to obtain the ground reference values did not substantially improve the final predictions in this 
study. A slight improvement was observed (Table 4), but the difference between the two approaches was not found to be statistically significant.

Lindberg et al. [38] modelled single-tree stem volume from ALS data using an approach in which TLS-derived DBH was used with an allometric model to produce single-tree ground reference volume. The approach taken by Lindberg et al. [38] can be viewed as a combination of the two methods tested in the present study, since both TLS data and an allometric model were used. In contrast to the present study, Lindberg et al. used TLS data from only one scan position per plot. The TLS-based approach was by Lindberg et al. compared to an approach based on manual measurements of $\mathrm{DBH}$, i.e., an approach without the use of TLS. The RMSE from a validation of the two approaches found by Lindberg et al. were $34.6 \%$ and $34.5 \%$ for the approach with and without the use of TLS, respectively. The results were thus relatively similar to the results obtained for crown biomass estimation in the present study.

Kankare et al. [20] estimated single crown biomass from multiple-scan TLS data and used variable selection to build predictive models from a range of geometrically and statistically TLS-derived features. Field reference biomass was measured trough destructive sampling, and Norway spruce was one of two species considered. The RMSE for Norway spruce crown biomass in that study was $38.13 \%$, which is slightly higher than the corresponding error observed in the present study. In another study, Kankare et al. investigated the estimation of Norway spruce crown biomass from ALS data [12]. The ground reference biomass was obtained through destructive sampling, and the RMSE for Norway spruce crown biomass was $77.5 \%$, which is higher than the error obtained in the present study.

Popescu [8] estimated single-tree total aboveground biomass of pine trees using a two-step procedure with ALS-predicted DBH and existing allometric models, corresponding to the one used in the present study (Section 2.5.5). Popescu reported an RMSE of 33\%. Accuracies obtained in the present study are in line with this and, as such, validate the results found by Popescu [8].

Both approaches in the present study consisted of two steps of modelling, illustrated in Figure 3. Both of these steps will have errors associated with them, adding up to the total error observed in the validation. The errors obtained from each individual model can give some indications on their relative contribution to the total error. The so-called out-of-bag prediction errors for the TLS biomass model, that is, the first step of the approach labelled "A" in Figure 3, corresponded to an RMSE of 34.0\%. A cross-validation of the ALS crown biomass model - the next step in approach "A" - gave an RMSE of 43.1\%. Based on this and the errors found by Hauglin et al. [11,19], it seems like both of the modelling steps in this approach contribute more or less equally to the total error. In the other approach, labelled "B" in Figure 3, it is likely that the errors from the allometric crown biomass model constitutes a larger part of the total errors. The mean percentage error associated with allometric crown biomass used in the present study is reported to be 40.2\% [25], whereas the RMSE from the cross-validation of the ALS-DBH model was $15.5 \%$. This is in line with findings in other studies in which DBH has been found to be well described by ALS features [4].The derivation of TLS features in the present study included several manual and semi-manual operations, such as, for example, setting the crown base height and measuring the crown width. These manual operations were conducted in such a way that they, in principle, could have been done automatically, solely using the TLS data. The methodology and specific algorithms to automatically perform these tasks are, to our knowledge, not readily 
available, and expected errors and accuracy of such an automated approach could be further investigated. The TLS model in the present study was trained using data derived through destructive sampling. In an operational inventory, high costs will prohibit the collection of such data. Using existing TLS models might be a viable solution, and since the crown properties are measured directly, the model might be less sensitive to regional or local stand-level allometric differences. The transferability of TLS models between regions, possibly with data from different instruments, could thus be subject to further research. In the present study, only Norway spruce trees were considered, and since crown shape and structure can differ, the performance of the proposed methods when applied to other tree species could also be investigated further.

Further development and optimization of the TLS-crown biomass model itself, such as considering other variables or reducing the number of variables, could improve the overall performance of the TLS-based approach.

There were three seasons of growth between the acquisition of ALS and TLS data. This might have affected the performance of the models, but we assume, however, these effects to be small.

The number of trees on sample plots from the study area was used as auxiliary information in the segmentation process. Single-tree segmentation can be carried out without the use of this auxiliary data, if it is not available. This was, however, not done in the present study, and thus, the effect on the accuracy of the predicted crown biomass with such a segmentation was not assessed.

In the data material used for validation, no segment contained more than one destructively sampled tree. The effect of predicting crown biomass for segments consisting of more than one tree was therefore not assessed, although such segments are likely to occur in an ALS-based single-tree inventory [33]. With the approach described in Section 2.5.5, the ALS model must, in such multi-tree segments, predict large DBH values to produce accurate crown biomass estimates. If not, crown biomass will be underestimated for these segments. The ALS-derived crown volume of a multi-tree segment might, to a larger extent, maintain the same relationship to the actual crown biomass as in single-tree segments than the ALS-predicted DBH. If this is the case, then the presence of multi-tree segments would increase the difference between the two approaches discussed in the present paper. More research is, however, needed to clarify this.

\section{Conclusions}

To conclude, we have shown that good predictions of single-tree crown biomass of Norway spruce can be derived from ALS data, using TLS to obtain the ground reference values. However, when compared to the approach without the use of TLS, the prediction accuracy was only slightly better. Thus, the use of TLS in this context should be considered in the light of the more extensive field work and data processing needed, but one should also take into account other possible benefits from using TLS.

\section{Acknowledgments}

We wish to thank Blom Geomatics, Norway, and Geoplan 3D, Norway, for providing and partly processing the laser data. We further wish to thank Janka Dibdiakova at The Norwegian Forest and Landscape Institute for doing the lab work. We are also grateful to Arne Drømtorp, Leif Kjøstelsen 
and Espen Martinsen (The Norwegian Forest and Landscape Institute); Vegard Lien, John Gunnar Dokk and Tord Storbækken (Norwegian University of Life Sciences), who took part in the field work. We finally want to thank the anonymous reviewers who contributed constructive and helpful comments and suggestions.

\section{Conflicts of Interest}

The authors declare no conflict of interest.

\section{References}

1. Maltamo, M.; Packalén, P.; Kallio, E.; Kangas, J.; Uuttera, J.; Heikkilä, J. Airborne laser scanning based stand level management inventory in Finland. In Proceedings of the Silvilaser 2011, Hobart, Australia, 16-19 October 2011.

2. Næsset, E. Predicting forest stand characteristics with airborne scanning laser using a practical two-stage procedure and field data. Remote Sens. Environ. 2002, 80, 88-99.

3. Hyyppä, J.; Kelle, O.; Lehikoinen, M.; Inkinen, M. A segmentation-based method to retrieve stem volume estimates from 3-D tree height models produced by laser scanners. IEEE Trans. Geosci. Remote Sens. 2001, 39, 969-975.

4. Persson, A.; Holmgren, J.; Söderman, U. Detecting and measuring individual trees using an airborne laser scanner. Photogramm. Eng. Remote Sens. 2002, 68, 925-932.

5. Solberg, S.; Næsset, E.; Bollandsås, O.M. Single Tree Segmentation Using Airborne Laser Scanner Data in a Structurally Heterogeneous Spruce Forest. Photogramm. Eng. Remote Sens. 2006, 72, 1369-1378.

6. Ene, L.; Næsset, E.; Gobakken, T. Single tree detection in heterogeneous boreal forests using airborne laser scanning and area-based stem number estimates. Int. J. Remote Sens. 2012, 33, 5171-5193.

7. Straub, C.; Koch, B. Estimating Single Tree Stem Volume of Pinus sylvestris Using Airborne Laser Scanner and Multispectral Line Scanner Data. Remote Sens. 2011, 3, 929-944.

8. Popescu, S.C. Estimating biomass of individual pine trees using airborne lidar. Biomass Bioenergy 2007, 31, 646-655.

9. Vauhkonen, J. Estimating crown base height for Scots pine by means of the 3D geometry of airborne laser scanning data. Int. J. Remote Sens. 2010, 31, 1213-1226.

10. Roberts, S.D.; Dean, T.J.; Evans, D.L.; McCombs, J.W.; Harrington, R.L.; Glass, P.A. Estimating individual tree leaf area in loblolly pine plantations using LiDAR-derived measurements of height and crown dimensions. For. Ecol. Manag. 2005, 213, 54-70.

11. Hauglin, M.; Dibdiakova, J.; Gobakken, T.; Næsset, E. Estimating single-tree branch biomass of Norway spruce by airborne laser scanning. ISPRS J. Photogramm. Remote Sens. 2013, 79, 147-156.

12. Kankare, V.; Räty, M.; Yu, X.; Holopainen, M.; Vastaranta, M.; Kantola, T.; Hyyppä, J.; Hyyppä, H.; Alho, P.; Viitala, R. Single tree biomass modelling using airborne laser scanning. ISPRS J. Photogramm. Remote Sens. 2013, 85, 66-73. 
13. Simonse, M.; Aschoff, T.; Spiecker, H.; Thies, M. Automatic Determination of Forest Inventory Parameters Using Terrestrial Laserscanning. In Proceedings of the ScandLaser Scientific Workshop on Airborne Laser Scanning of Forests, Umeå, Sweden, 3-4 September 2003; pp. $251-257$.

14. Bienert, A.; Scheller, S.; Keane, E.; Mohan, F.; Nugent, C. Tree Detection and Diameter Estimations by Analysis of Forest Terrestrial Laser Scanner Point Clouds. In Proceedings of the ISPRS Commission III Workshop 36, part 3. Espoo, Finland, 12-14 September 2007; pp. 50-55.

15. Lovell, J.L.; Jupp, D.L.B.; Newnham, G.J.; Culvenor, D.S. Measuring tree stem diameters using intensity profiles from ground-based scanning lidar from a fixed viewpoint. ISPRS J. Photogramm. Remote Sens. 2011, 66, 46-55.

16. Moskal, L.M.; Zheng, G. Retrieving forest inventory variables with Terrestrial Laser Scanning (TLS) in urban heterogeneous forest. Remote Sens. 2012, 4, 1-20.

17. Yao, T.; Yang, X.; Zhao, F.; Wang, Z.; Zhang, Q.; Jupp, D.; Lovell, J.; Culvenor, D.; Newnham, G.; Ni-Meister, W.; et al. Measuring forest structure and biomass in New England forest stands using Echidna ground-based lidar. Remote Sens. Environ. 2011, 115, 2965-2974.

18. Holopainen, M.; Vastaranta, M.; Kankare, V.; Räty, M.; Vaaja, M.; Liang, X.; Yu, J.; Hyyppä, H.; Hyyppä, R. Biomass estimation of individual trees using stem and crown diameter TLS measurements. In Proceedings of the ISPRS Workshop on Laser Scanning, Calgary, AB, Canada, 29-31 August 2011; Volume XXXIII.

19. Hauglin, M.; Astrup, R.; Gobakken, T.; Næsset, E. Estimating single-tree branch biomass of Norway spruce with terrestrial laser scanning using voxel-based and crown dimension features. Scand. J. For. Res. 2013, 28, 456-469.

20. Kankare, V.; Holopainen, M.; Vastaranta, M.; Puttonen, E.; Yu, X.; Hyyppä, J.; Vaaja, M.; Hyyppä, H.; Alho, P. Individual tree biomass estimation using terrestrial laser scanning. ISPRS J. Photogramm. Remote Sens. 2013, 75, 64-75.

21. Hauglin, M.; Gobakken, T.; Lien, V.; Bollandsås, O.M.; Næsset, E. Estimating potential logging residues in a boreal forest by airborne laser scanning. Biomass Bioenergy 2012, 36, 356-365.

22. Boudreau, J.; Nelson, R.F.; Margolis, H.A.; Beaudoin, A.; Guindon, L.; Kimes, D.S. Regional aboveground forest biomass using airborne and spaceborne LiDAR in Québec. Remote Sens. Environ. 2008, 112, 3876-3890.

23. Næsset, E.; Gobakken, T. Estimation of above- and below-ground biomass across regions of the boreal forest zone using airborne laser. Remote Sens. Environ. 2008, 112, 3079-3090.

24. Zianis, D.; Muukkonen, P.; Mäkipää, R.; Mencuccini, M. Biomass and Stem Volume Equations for Tree Species in Europe. Silva Fenn. 2005, 1-63.

25. Marklund, L.G. Biomass functions for pine, spruce and birch in Sweden; Swedish University of Agricultural Sciences: Umeå, Sweden, 1988.

26. Næsset, E.; Gobakken, T.; Solberg, S.; Gregoire, T.G.; Nelson, R.; Ståhl, G.; Weydahl, D. Model-assisted regional forest biomass estimation using LiDAR and InSAR as auxiliary data: A case study from a boreal forest area. Remote Sens. Environ. 2011, 115, 3599-3614.

27. Maltamo, M.; Bollandsås, O.M.; Vauhkonen, J.; Breidenbach, J.; Gobakken, T.; Næsset, E. Comparing different methods for prediction of mean crown height in Norway spruce stands using airborne laser scanner data. Forestry 2010, 83, 257-268. 
28. Hasegawa, H.; Yoshimura, T. Estimation of GPS positional accuracy under different forest conditions using signal interruption probability. J. For. Res. 2007, 12, 1-7.

29. Andersen, H.-E.; Clarkin, T.; Winterberger, K.; Strunk, J. An Accuracy Assessment of Positions Obtained Using Survey- and Recreational-Grade Global Positioning System Receivers across a Range of Forest Conditions within the Tanana Valley of Interior Alaska. West. J. Appl. For. 2009, 24, 128-136.

30. Næsset, E. Point accuracy of combined pseudorange and carrier phase differential GPS under forest canopy. Can. J. For. Res. 1999, 29, 547-553.

31. Breidenbach, J.; Næsset, E.; Lien, V.; Gobakken, T.; Solberg, S. Prediction of species specific forest inventory attributes using a nonparametric semi-individual tree crown approach based on fused airborne laser scanning and multispectral data. Remote Sens. Environ. 2010, 114, 911-924.

32. Axelsson, P. DEM generation form laser scanner data using adaptive TIN models. Int. Arch. Photogramm. Remote Sens. 2000, XXXIII, 110-117.

33. Vauhkonen, J.; Ene, L.; Gupta, S.; Heinzel, J.; Holmgren, J.; Pitkanen, J.; Solberg, S.; Wang, Y.; Weinacker, H.; Hauglin, K.M.; et al. Comparative testing of single-tree detection algorithms under different types of forest. Forestry 2012, 85, 27-40.

34. Carr, J.C.; Beatson, R.K.; Cherrie, J.B.; Mitchell, T.J.; Fright, W.R.; McCallum, B.C.; Evans, T.R. Reconstruction and Representation of 3D Objects with Radial Basis Functions. In Proceedings of the 28th Annual Conference on Computer Graphics and Interactive Techniques, Los Angeles, CA, USA, 12-17 August 2001; ACM Press: New York, NY, USA, 2001; pp. 67-76.

35. R Development Core Team. $R$ : A Language and Environment for Statistical Computing; $\mathrm{R}$ Foundation for Statistical Computing: Vienna, Austria, 2011.

36. Breiman, L. Random Forests. Mach. Learn. 2001, 45, 5-32.

37. Hastie, T.; Tibshirani, R.; Friedman, J. The Elements of Statistical Learning: Data Mining, Inference, and Prediction, 2nd ed.; Springer: New York, NY, USA, 2009.

38. Lindberg, E.; Holmgren, J.; Olofsson, K.; Olsson, H. Estimation of stem attributes using a combination of terrestrial and airborne laser scanning. Eur. J. For. Res. 2012, 131, 1917-1931.

(C) 2014 by the authors; licensee MDPI, Basel, Switzerland. This article is an open access article distributed under the terms and conditions of the Creative Commons Attribution license (http://creativecommons.org/licenses/by/3.0/). 